Fluid Boundaries 



\title{
Fluid Boundaries
}

Forming and Transforming Identity in Nepal

\author{
William F. Fisher
}

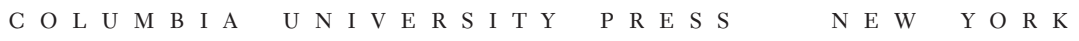


C O L U M B I A U N I E R S T Y P R E S S

Publishers Since 1893

New York, Chichester, West Sussex

Copyright (C) 2001 Columbia University Press

All rights reserved

Library of Congress Cataloging-in-Publication Data

Fisher, William F., 1951-

Fluid boundaries : forming and transforming identity in Nepal / William F. Fisher p. $\mathrm{cm}$.

Includes bibliographic references and index.

ISBN 0-231-11086-3 (cloth)

ISBN 0-231-11087-1 (paper)

Thakali (Nepalese people)_Ethnic identity.

2. Thakali (Nepalese people)-Social life and customs.

1. Title.

DS493.9.T45 F57 2001

305.891'495-dc21

(®)

Columbia University Press books are printed on permanent and durable acid-free paper.

Printed in the United States of America

$\begin{array}{lllllllllll}\text { c } & 10 & 9 & 8 & 7 & 6 & 5 & 4 & 3 & 2 & 1\end{array}$

$\begin{array}{lllllllllll}\mathrm{P} & 10 & 9 & 8 & 7 & 6 & 5 & 4 & 3 & 2 & 1\end{array}$ 
You can't step into the same river twice. - -Heraclitus, "Cratylus"

Each time I remember Fragment 91 of Heraclitus: 'You will not go down twice to the same river,' I admire his dialectic still, because the facility with which we accept the first meaning ("The river is different') clandestinely imposes the second one ('I am different') and gives us the illusion of having invented it.

- Jorge Luis Borges, "New Refutation of Time," Other Inquisitions 
